\title{
What motivates high vowel deletion in Québec French: Foot structure or tonal profile?
}

\author{
Natália Brambatti Guzzo, Heather Goad \& Guilherme D. Garcia*
}

\begin{abstract}
Previous studies have argued that high vowel deletion (HVD) in Québec French is constrained by iterative iambic footing (Guzzo, Goad \& Garcia 2016, Garcia, Goad \& Guzzo 2017; see also Verluyten 1982), since it preferentially applies in even-numbered syllables from the right edge of the word. In this paper, we compare this hypothesis with an alternative hypothesis: HVD is constrained by the optionally-realized phrase-initial H tone (Jun \& Fougeron 2000, Thibault \& Ouellet 1996). We report on a judgement task in which two- and four-syllable nouns with HVD in the initial syllable are placed in phrases of different profiles (No determiner, Determiner + noun, Determiner + adjective + noun). If tonal profile plays a role in HVD, HVD in four-syllable nouns in phrases where the noun is in isolation or preceded by a determiner alone should be dispreferred, since the initial syllable of the noun is assigned the optional $\mathrm{H}$ tone in these contexts. Our results do not confirm this: HVD is favored in four-syllable nouns over two-syllable nouns, regardless of phrase type. We explain this finding by expanding our previous proposal: HVD is regulated by foot structure, but is dispreferred when it targets the head foot (where the obligatory phrase-final prominence is realized).
\end{abstract}

Keywords. high vowel deletion; phrasal prominence; footing; Québec French

1. Introduction. In the literature on prosodic phonology, it is assumed that prosodic domains are identified on the basis of the phonological processes that they exhibit (see, e.g., Nespor \& Vogel 1986, McCarthy \& Prince 1995, Vogel 2009). For example, if two structures display identical prominence patterns, they will be assigned to the same prosodic domain. Thus, the proposal that a language lacks a given prosodic domain usually relies on the absence of phonological phenomena associated with that domain.

This is the case for the foot in French. In several varieties of French, including European and Québec French, prominence is obligatory only at the right edge of the phonological phrase (PPh), with the optional assignment of a high tone to the initial syllable of the first lexical word in the domain (see Dell 1984, Jun \& Fougeron 2000 for European French, and Thibault \& Ouellet 1996 for Québec French). French would then be different from languages such as English, in which stress is manifested in lower prosodic domains: it is realized in the foot and computed in the phonological word (PWd) (Liberman \& Prince 1977, Hayes 1995). The lack of evidence from prominence patterns in the foot domain in French has led to the assumption that the language lacks foot structure (Jun \& Fougeron 2000). Thus, while prominence in English would require the foot and PWd domains (1), the manifestation of prominence in French would only require the $\mathrm{PPh}(2)$. Figure 1 illustrates this. ${ }^{1}$

\footnotetext{
* We would like to thank Amélie Bernard, Jeff Lamontagne, Eva Portelance, Morgan Sonderegger, Francisco Torreira, and Yvan Rose for their input on various aspects of this work. This work was supported by grants from the Social Sciences and Humanities Research Council of Canada and le Fonds de recherche du Québec - Société et culture. Authors: Natália Brambatti Guzzo, McGill University (nataliaguzzo@me.com), Heather Goad, McGill University (heather.goad@mcgill.ca) \& Guilherme D. Garcia, Ball State University (gdgarcia@bsu.edu).

${ }^{1}$ The PWd is included in the prosodic hierarchy for French in Figure 1 since there is evidence for this domain from several segmental processes (see, e.g., Charette 1991, Hannahs 1995, Scullen 1997).
} 
(1) Prominence in English

$\left[(, æ v ə)_{\mathrm{Ft}}(\mathrm{ka}:)_{\mathrm{Ft}} \mathrm{dov}\right]_{\mathrm{PWd}}$

'avocado'

(2) Prominence in (Québec) French $\left(\mathrm{H}^{*}\right.$ indicates obligatory phrase-final prominence)

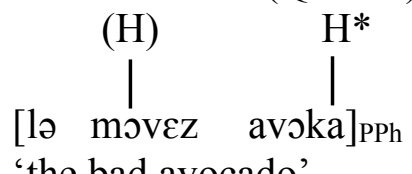

'the bad avocado'

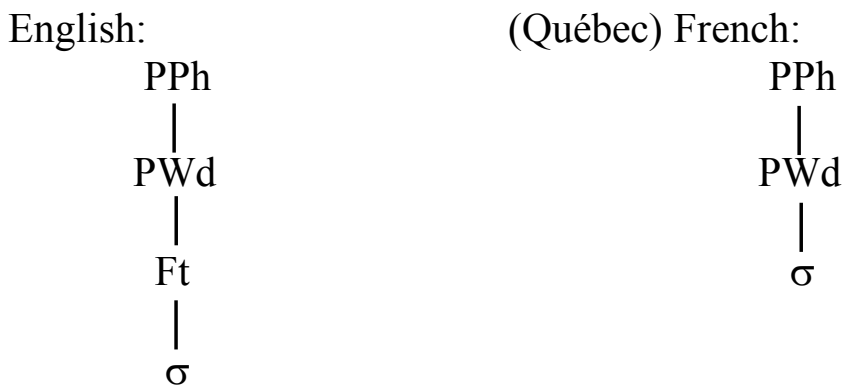

Figure 1. Partial prosodic hierarchy for English (on the left) and French (on the right). Based on evidence from prominence patterns, the foot domain would be absent in French.

However, it is possible that even though footing in (Québec) French cannot be motivated based on prominence patterns, it can be motivated through the application of certain segmental processes. In effect, Verluyten (1982) suggested that variable high vowel deletion (HVD) in Québec French $(\mathrm{QF})$ is sensitive to alternating rhythmic structure: assuming that $\mathrm{QF}$ alternates strong and weak syllables from the right edge of the word (in words that do not end in a schwa), HVD would be preferred in weak syllables; ${ }^{2}$ see Figure 2.

\section{HVD preferred:}

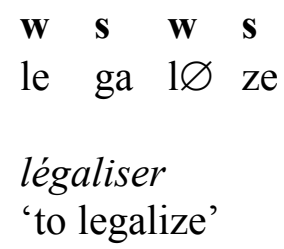

\section{HVD dispreferred:}

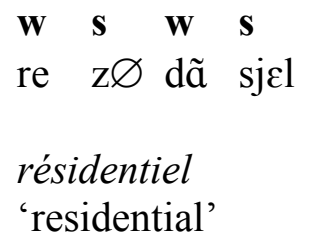

Figure 2. High vowel deletion patterns in Québec French (Verluyten 1982).

Even though Verluyten (1982) did not test this empirically, the results of a recent experiment on native speakers' judgements on HVD in QF support the proposal that the phenomenon is rhythmically conditioned: participants prefer HVD in even-numbered syllables from the right edge of

\footnotetext{
2 The hypothesis that HVD in QF is constrained by word-internal rhythmic patterns has been challenged by evidence from sociolinguistic data, which suggest instead that the phenomenon is strongly conditioned by phonotactics (Cedergren 1986).
} 
the word (Guzzo, Goad \& Garcia 2016, Garcia, Goad \& Guzzo 2017). We refer to this as the footing hypothesis.

Since this experiment included only isolated words, however, the possibility cannot be refuted that the rhythm constraining HVD is instead the phrase-level tonal profile observed in the language. We refer to this as the tonal hypothesis. We situate this hypothesis as follows: since a LHLH* contour is assigned to phrases in French with the initial L normally being realized on function words, it could be the case that HVD does not target syllables that fall in positions that would receive the following $H$. This would be consistent with the observation that French lacks word-level stress and would provide further support for the prosodic hierarchy in Figure 1 for French.

This paper strives to tease apart these two hypotheses by examining the influence of footing versus phrase-level tonal profile on HVD in QF. We probe this issue by conducting a judgement task in which the target words are presented to participants both in phrases and in isolation.

In section 2, we briefly examine the findings of our previous experiment, in order to discuss the potential role of footing in HVD as well as to situate the research questions that the present experiment strives to address. In section 3, we describe the methodology of the new experiment, and in section 4, we discuss the results. Section 5 concludes.

2. Previous experiment. As mentioned above, our previous experiment supports Verluyten's (1982) hypothesis that HVD in QF is conditioned by word-internal rhythmic structure (Guzzo, Goad \& Garcia 2016, Garcia, Goad \& Guzzo 2017). This section describes the methodology and results of this experiment.

The experiment included two- to six-syllable words where the target vowel [i] was either deleted or produced in various positions. [i] was never deleted word-finally, following a branching onset, or preceding a coda, since HVD is blocked ${ }^{3}$ in these contexts (see, e.g., Walker 1984, Cedergren 1986). Additionally, no target word ended in a schwa. The target items were recorded by a native speaker of QF with training in linguistics and phonetics. The items were presented in isolation, both auditorily and orthographically. The participants, who were all native speakers of QF from the Montreal area, had to judge whether the word that they heard was pronounced in a natural way using a five-point scale.

The results ${ }^{4}$ indicate that HVD was rated significantly better when it occurs in evennumbered syllables from the right edge of the word; see Figure 3. In other words, HVD was perceived as more natural in items such as kõ(bØ.ne) combiner 'to combine' and $\mathrm{ma}(\mathrm{n} \varnothing . \mathrm{f} \varepsilon \mathrm{s})($ ta.sjã) manifestation 'demonstration' than in items such as or(ga.n $\varnothing$ )(za.tœr) organisateur 'organizer' and (ka.p $\varnothing)($ ta.li)(za.sjõ) capitalisation 'capitalization'. As previously mentioned, even-numbered syllables are associated with weak positions in words that do not end in a schwa (Verluyten 1982). Assuming that strong positions correspond to foot heads, we concluded that HVD in QF is favored in foot-dependent position and disfavored in foot-head position. The finding that there was no significant difference in deletion preferences for syllable

\footnotetext{
${ }^{3}$ Cedergren (1986) reports a few examples of HVD in closed syllables, and Verluyten (1982) provides some examples of HVD following complex onsets. However, HVD is highly constrained in such contexts, given that the resulting form is articulatorily challenging.

${ }^{4}$ Participants' responses were modeled with hierarchical logistic regressions with by-speaker and by-item random intercepts.
} 
two versus syllable four (from the right word edge) nor for syllable three versus syllable five is consistent with the hypothesis that footing in QF is iambic and iterative.
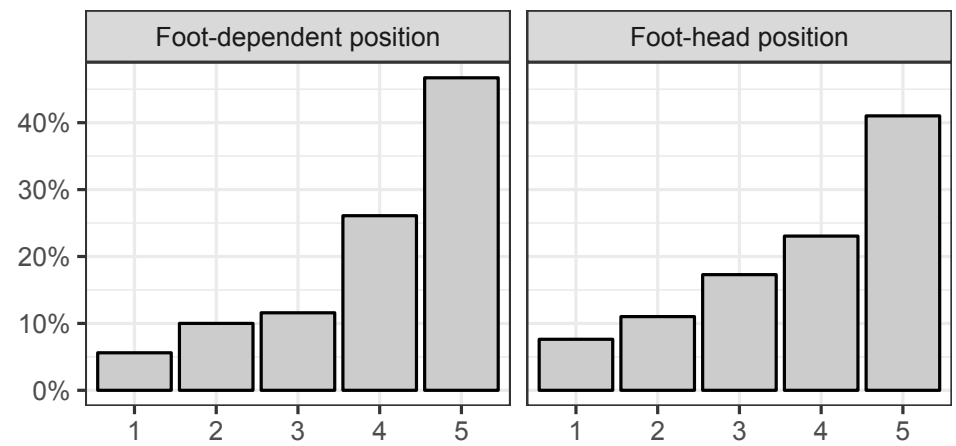

Figure 3. Participants' responses by position of the target vowel within the word ( 5 = completely natural; Garcia, Goad \& Guzzo 2017).

While the results illustrated in Figure 3 suggest that HVD is conditioned by footing, another finding from our previous experiment is puzzling: in foot dependent position, HVD is dispreferred when it applies in the word-initial syllable (3).

HVD is dispreferred word-initially in QF (Guzzo, Goad \& Garcia 2016)
$\begin{array}{llll}(\mathrm{f} \varnothing .1 \varepsilon)< & \mathrm{k} \tilde{\mathrm{D}}(\mathrm{b} \varnothing . \mathrm{ne}) & (\mathrm{f} \varnothing . \mathrm{na})(\mathrm{li} . \mathrm{te})< & \operatorname{ma}(\mathrm{n} \varnothing . \mathrm{f} \varepsilon \mathrm{s})(\mathrm{ta} . \mathrm{sj} \tilde{\mathrm{o}}) \\ \text { filet } & \text { combiner } & \text { finalité } & \text { manifestation } \\ \text { 'net' } & \text { 'to combine' } & \text { 'finality' } & \text { 'demonstration' }\end{array}$

The question that arises is whether HVD in QF is constrained by another variable, one that accounts for its disfavored application in word-initial position. ${ }^{5}$ If this were the case, then the role of footing in the phenomenon could be weakened. Since the experiment reported in Guzzo, Goad \& Garcia (2016) and Garcia, Goad \& Guzzo (2017) only included isolated words, it did not test for the possibility that another rhythmic constraint, namely phrase-level tonal profile, could play a role in HVD. More specifically, it could be that the phenomenon is conditioned by the location of the optionally-realized phrase-initial $\mathrm{H}$ tone. This would explain participants' dispreference for HVD in the initial syllable of lexical words, since that is the syllable where the optional $\mathrm{H}$ tone is most commonly realized.

In this paper, we contrast the footing hypothesis with the hypothesis that the tonal profile of the PPh has an effect on HVD in QF (the tonal hypothesis). To do so, we conducted another judgement task, which contained words in isolation as well as words in phrases of different profiles. The next section describes the methodology of this experiment, as well as our predictions for the types of phrases included in it.

3. HVD and phrase-level tonal profile. This section describes the methodology for the experiment that we conducted in order to examine whether the optionally realized $\mathrm{H}$ tone in phraseinitial position in QF affects participants' preferences for HVD.

3.1. PARTICIPANTS. We recruited 12 native speakers of Québec French, all of whom were born and raised in the Montreal area. None of the participants was bilingual from childhood (although

\footnotetext{
${ }^{5}$ In Garcia, Goad \& Guzzo (2017), we also report that morphology (i.e., whether the target vowel is in a suffix) and phonotactic profile (i.e., whether the resulting consonant cluster mirrors a phonotactically well-formed complex onset) have an effect on HVD in QF.
} 
some reported having varying levels of proficiency in other languages, including English). Additionally, none of the participants reported any hearing impairments.

3.2. STIMULI. The experiment included 120 two- and four-syllable nouns with and without deletion of [i] in the first syllable. Similarly to the previous experiment, the deletable vowel never followed a branching onset or preceded a coda. Additionally, the consonantal string that resulted from HVD always mirrored an ill-formed branching onset.

The target items were inserted in three types of phrases (4). The vowel targeted by HVD is highlighted in the examples in (4).

(4) Types of phrases in the present experiment:

a. No determiner $(\mathrm{N})$

\begin{tabular}{|c|c|c|}
\hline vizaz & visage & 'face' \\
\hline vīizitasjõ & Visitation & 'visitation' \\
\hline \multicolumn{3}{|c|}{ b. Determiner + noun $(\mathrm{DN})$} \\
\hline lə vizaz & le visage & 'the face' \\
\hline la vịizitasj̃̃ & la Visitation & 'the visitation' \\
\hline \multicolumn{3}{|c|}{ c. Determiner + adjective + noun $(\mathrm{DAN})$} \\
\hline lə joli vizzaz & le joli visage & 'the beautiful face' \\
\hline la joli vīzitasjõ & la jolie Visitation & 'the beautiful visitation' \\
\hline
\end{tabular}

The stimuli were recorded by a female native speaker of Québec French with training in linguistics and phonetics. Since HVD was produced naturally, the absence of [i] in the stimuli with HVD was later checked in Praat (Boersma \& Weenink 2018).

The stimuli also included 282 fillers, which exhibited presence or absence of deletion of non-high vowels (both in isolated words and in words placed in phrases) and change of voicing in word-medial fricatives. The total number of items that each participant judged was 402 .

3.3. Procedure. The experiment was constructed in Praat. Similarly to the previous experiment, the stimuli were presented both auditorily and in orthographic form. To prevent spill-over effects, stimuli were separated by a beep. While the beep and the item played, participants saw a blank screen. They were only able to see the orthographic form for each stimulus after hearing it. Orthographic presentation of the stimuli was necessary so as to parallel the previous experiment and to ensure that participants were certain of the lexical item or phrase that they were judging. Participants judged how natural the stimuli sounded using a four-point scale ranging from completely unnatural to completely natural. The order of the stimuli was pseudorandomized. Participants were tested individually in a sound-attenuated booth in the Department of Linguistics at McGill University. Each session took approximately 45 minutes, with two fiveminute breaks included. Participants were compensated for their time.

3.4. PREDiCTIONS. In this section, we compare the predictions of the tonal and footing hypotheses. We begin with the tonal hypothesis. Given that the tonal profile of phrases containing twoor four-syllable nouns is different, we have distinct predictions depending on the number of syllables present in the target noun. We start by detailing our predictions for phrases containing four-syllable nouns. Figure 4 shows the tonal profile of phrases with nouns of this length. Recall that $\mathrm{H}^{*}$ indicates the obligatory phrase-final prominence. 


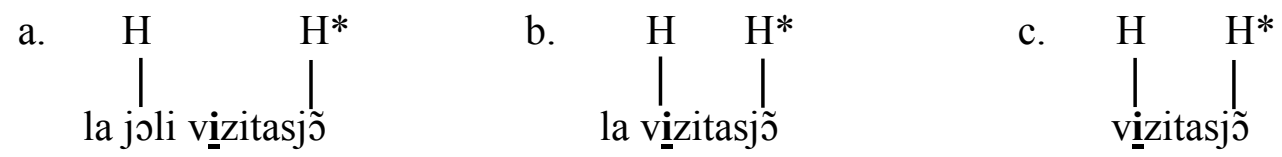

Figure 4. Tonal profile of target items containing four-syllable nouns. The deletable vowel is highlighted.

With regard to phrases containing a four-syllable noun, we predict the following:

(i) HVD should be preferred in DAN (a in Figure 4). Since the optional phrase-initial H tone should fall on the first syllable of the adjective, the first syllable of the noun is prosodically weaker, and thus should be more susceptible to HVD.

(ii) HVD should be dispreferred in DN and N (b and c in Figure 4, respectively). In both cases, the targeted vowel is in the syllable where the phrase-initial $\mathrm{H}$ should fall.

(iii) If there is a difference between DN and N, HVD should be preferred in DN, since, in this case, the targeted vowel is not in absolute initial position in the PPh.

Figure 5 shows the tonal profile of the three types of phrases containing two-syllable nouns included in our stimuli.
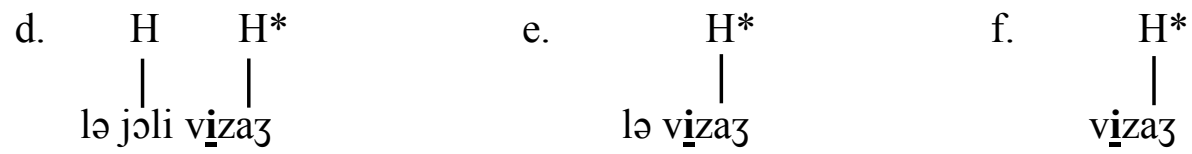

Figure 5. Tonal profile of target items containing two-syllable nouns. The deletable vowel is highlighted.

Given the representations in Figure 5, the following are our predictions for phrases containing a two-syllable noun:

(iv) HVD should be equally favored in DAN, DN and N (d, e and $f$ in Figure 5, respectively), but for distinct reasons. DAN phrases with a two-syllable noun have the same tonal profile as DAN phrases with a four-syllable noun. Therefore, if HVD is favored in DAN with four-syllable nouns, it should also be favored in DAN with two-syllable nouns. In the case of DN and N, the optional initial $\mathrm{H}$ tone cannot be realized due to clash. In this case, the targeted vowels are in prosodically weaker positions and are thus subject to HVD.

(v) If there is a difference between DN and N, HVD should be favored in DN, i.e., in phrases where the targeted vowel is not in absolute initial position in the phrase, mirroring prediction (iii) for four-syllable nouns.

We turn now to the footing hypothesis. If word-internal footing plays a role in HVD, in line with our previous results (Guzzo, Goad \& Garcia 2016, Garcia, Goad \& Guzzo 2017) and Verluyten's (1982) proposal, the following is predicted:

(vi) Since the target vowel is in foot-dependent position in all contexts, there should be no difference between two- and four-syllable nouns, nor between any of the phrase types. HVD should be equally natural in all contexts.

In summary, we predict that, if phrase-level tonal profile affects native speakers' preferences for HVD, two- and four-syllable nouns should behave differently, and so should the distinct phrase types. If, on the other hand, footing constrains HVD, participants should judge HVD to be good for all types of phrases and noun profiles. In the next section, we discuss the results of our experiment. 
4. Results and analysis. Figure 6 shows the rates of 'good' responses for both two- and foursyllable nouns, and for the three types of phrases included in the experiment. Responses 3 and 4 (on the four-point scale used) were collapsed so as to make the plot clearer.
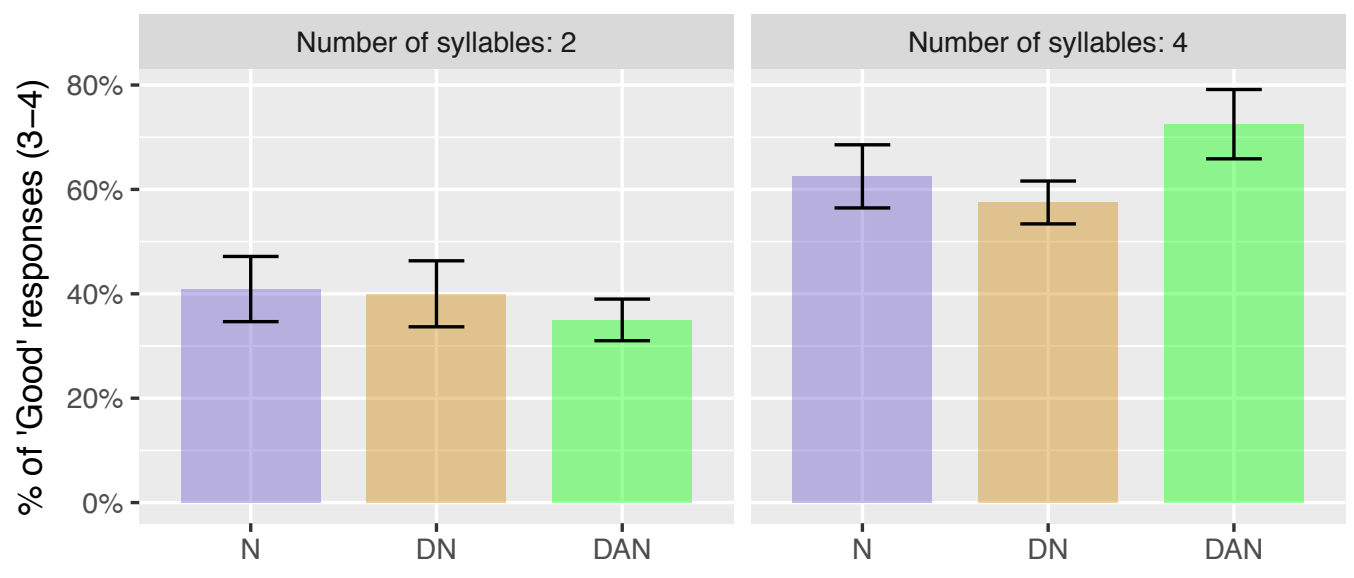

Figure 6. HVD preference by number of syllables in the target noun and type of phrase.

Examination of Figure 6 indicates that all types of phrases containing four-syllable nouns were consistently rated better than all types of phrases containing two-syllable nouns. Additionally, the plot suggests that there is no statistical difference between the types of phrases for twosyllable nouns. For four syllable nouns, the plot suggests that DAN might be significantly different from the other phrases (in particular, from DN).

The data were modeled using hierarchical logistic regressions with by-speaker and by-item random intercepts in R (R Core Team 2018). We ran a general statistical model and two submodels. The general model included the interaction between number of syllables in the noun and type of phrase. The sub-models included only type of phrase as an independent variable and modeled two- and four-syllable nouns separately. Because the tonal hypothesis has multiple predictions, we detail expected and unexpected results for this hypothesis in (5).

(5) Tonal hypothesis:

a. Unexpected result 1: HVD is favored in four-syllable nouns relative to two-syllable nouns.

b. Unexpected result 2: Phrase type is not significant for four-syllable nouns.

c. Expected result: Phrase type is not significant for two-syllable nouns.

The first unexpected result is that HVD is rated significantly better in four-syllable nouns than in two-syllable nouns, as suggested by Figure $6(\hat{\beta}=1.4, z=2.55, p=0.01)$. As mentioned above, the tonal hypothesis predicts that, although DN and N should disfavor HVD for four-syllable nouns, HVD in two- and four-syllable nouns should be equally favored in DAN phrases. This result is also unexpected under the footing hypothesis, which predicts that, since the deletable vowel in both two- and four-syllable nouns is in foot-dependent position, HVD should be equally good for both types of nouns regardless of phrase type.

A possible explanation for this unexpected result stems from the differences in word length: HVD could be constrained by word length, given the commonly observed finding that longer words tend to be spoken more quickly (see, e.g., Lehiste 1970, Natatani, O'Connor \& 
Aston 1981; for French, see Malécot, Johnson \& Kizziar 1972). Considering that HVD is a weakening process, it should apply more frequently as word length increases.

If this were the case, then HVD and high vowel retention should yield inverse preferences: while HVD in four-syllable nouns should be better than HVD in two-syllable nouns, HV retention in four-syllable nouns should be worse than HV retention in two-syllable nouns. However, this is not observed in the data: there is no statistical difference for HV retention between twoand four-syllable nouns $(p>0.05)$. This result indicates that participants' preferences for HVD and HV retention are regulated not by word length, but by another factor.

We explain this unexpected result by resorting to our previous proposal that iterative iambic footing regulates HVD (Guzzo, Goad \& Garcia 2016, Garcia, Goad \& Guzzo 2017), with the additional proposal that the process is dispreferred when it targets the head foot in the domain. Consider the representations in Figure 7.

a.

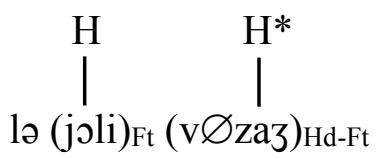

b.

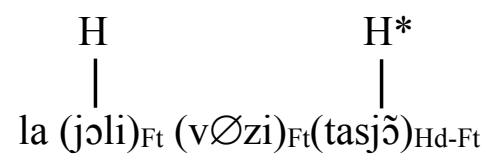

Figure 7. Foot structure for DAN phrases with two- and four-syllable nouns.

We propose that HVD is disfavored in two-syllable nouns relative to four-syllable nouns ( $\mathrm{a}$ and $\mathrm{b}$ in Figure 7, respectively) because, in phrases with two-syllable nouns, the deletable vowel is located in the head foot of the domain. In this case, the foot where the deletable vowel is will be assigned the obligatory phrasal prominence, which disfavors the application of any weakening process (such as HVD). As we will see the in the remainder of this section, the other two results of our statistical analysis, both the unexpected and the expected one under the tonal hypothesis in (5), are also compatible with a foot-based analysis.

The second unexpected result for the predictions of the tonal hypothesis is that phrase type is not a significant predictor for four-syllable nouns, unlike what is suggested by the error bars in the right panel of Figure $6 .^{6}$ According to the tonal hypothesis, HVD in four-syllable nouns should be preferred in longer (DAN) phrases than in shorter (DN or N) phrases, since in shorter phrases the deletable vowel is in the syllable where the optionally-realized initial $\mathrm{H}$ tone falls.

Although the tonal hypothesis cannot explain this unexpected result, the footing hypothesis can - with the addition of a role for the head foot. In phrases containing a four-syllable noun, HVD in the initial syllable will consistently target a foot-dependent position. Since the foot containing the target vowel is not the head foot in the domain, HVD in the initial syllable is favored.

Turning to the expected result under the tonal hypothesis, we observed that phrase type is not significant for two-syllable nouns. Although this is consistent with the tonal hypothesis, given the other results discussed above, it seems unlikely that this result truly supports the tonal hypothesis, as this would mean that tonal profile regulates HVD in phrases with two-syllable nouns, but not in phrases with four-syllable nouns. As previously mentioned, this result can also be accounted for by the footing hypothesis: HVD in two-syllable nouns is dispreferred, regardless of phrase type, because it consistently targets the head foot in the domain.

\footnotetext{
${ }^{6}$ The statistical models were conservative, given that they accounted for the variation among participants and items, which may explain why they do not capture the difference between phrases with four-syllable nouns suggested by the plot in Figure 6 .
} 
In summary, both the unexpected and expected results from our experiment can be accounted for by the hypothesis that HVD in QF is regulated by footing. In addition, the results indicate that native speakers' judgements are constrained by the position of the foot-dependent syllable in the domain: HVD is dispreferred when it occurs in the head foot, which coincides with the location where obligatory phrasal prominence is assigned.

5. Conclusion. The observation that (Québec) French lacks the typical signatures of word-level stress has led to the assumption that the language does not have foot structure (e.g., Jun \& Fougeron 2000). However, some segmental phenomena, such as HVD, have been proposed to be conditioned by word-internal rhythm (Verluyten 1982), or, more specifically, by alternating iambic feet (Guzzo, Goad \& Garcia 2016, Garcia, Goad \& Guzzo 2017). In this paper, we challenged our previous proposal that HVD in QF is constrained by footing. Since our previous experiment included only isolated words, it was not possible to refute the possibility that phraselevel tonal profile plays a role in HVD.

We hypothesized that HVD in QF could be constrained by the optionally-realized phraseinitial H tone (see, e.g., Thibault \& Ouellet 1996). More specifically, we predicted that HVD in the initial syllable of two- and four-syllable nouns in different phrase types would be rated differently by native speakers. Given the position of the initial H tone, HVD in two-syllable nouns was expected to be favored in the three types of phrases under analysis (No determiner, Determiner + noun, Determiner + adjective + noun), while HVD in four-syllable nouns was expected to be favored only in DAN.

Our results did not confirm our predictions: HVD was preferred in four-syllable nouns, regardless of type of phrase, and, for both four- and two-syllable nouns, type of phrase was not significant. We interpreted these results by returning to the proposal that HVD is regulated by iterative iambic footing and expanding it to include a novel observation: HVD is dispreferred in the head foot of the domain. This addition to our previous proposal accounts for the finding that HVD in two-syllable nouns is worse than in four-syllable nouns: in two-syllable nouns, the deletable vowel is contained in the head foot, which is assigned the obligatory phrasal prominence. Our proposal also accounts for the observation that there is no effect of phrase type on HVD in phrases containing either two- or four-syllable nouns.

One surprising finding was that judgements for nouns in isolation were not statistically different from judgements for Determiner + noun phrases, for both types of noun profiles. This is surprising because we expected that HVD in absolute initial position in the PPh might be dispreferred, as we observed in our earlier study. The results from the present experiment thus suggest that HVD goes against the common observation that languages strengthen the initial position of phonological domains (e.g., Keating et al. 2003). The potential dispreference for HVD in the initial syllable of the PPh should be further examined in a larger study.

\section{References}

Boersma, Paul \& David Weenink. 2018. Praat: Doing phonetics by computer [Computer program]. Version 6.0.37.

Charette, Monik. 1991. Conditions on phonological government. Cambridge: Cambridge University Press.

Cedergren, Henrietta J. 1986. Metrical structure and vowel deletion in Montreal French. In David Sankoff (ed.) Diversity and diachrony. 293-300. Philadelphia: John Benjamins. 
Dell, François. 1984. L'accentuation dans les phrases en français. In François Dell, Daniel Hirst \& Jean-Roger Vergnaud (eds.) Forme sonore du langage. 65-122. Paris: Hermann.

Garcia, Guilherme D., Heather Goad \& Natália Brambatti Guzzo. 2017. Footing is not always about stress: Formalizing variable High Vowel Deletion in Québec French. In Karen Jesney, Charlie O'Hara, Caitlin Smith \& Rachel Walker (eds.) Proceedings of the Annual Meeting on Phonology 2016.

Guzzo, Natália Brambatti, Heather Goad \& Guilherme D. Garcia. 2016. High Vowel Deletion in Québec French: Evidence for vestigial iambs. Paper presented at the 24th Manchester Phonology Meeting.

Hannahs, Stephen J. 1995. The phonological word in French. Linguistics 33(6). 1125-1144.

Hayes, Bruce. 1995. Metrical stress theory: Principles and case studies. Chicago: University of Chicago Press.

Jun, Sun-Ah \& Cécile Fougeron. 2000. A phonological model of French intonation. In Antonis Botinis (ed.) Intonation: Analysis, modelling and technology. 209-242. Dordrecht: Kluwer.

Keating, Patricia, Taehong Cho, Cécile Fougeron \& Chai-Shune Hsu. 2003. Domain-initial strengthening in four languages. In John Local, Richard Ogden, \& Rosalind Temple (eds.) Phonetic interpretation: Papers in laboratory phonology VI. 145-163. Cambridge: Cambridge University Press.

Lehiste, Ilse. 1970. Suprasegmentals. Cambridge, MA: MIT Press.

Liberman, Mark \& Alan Prince. 1977. On stress and linguistic rhythm. Linguistic Inquiry, 8(2). 249-336.

Malécot, A., R. Johnston \& P.-A. Kizziar. 1972. Syllabic rate and utterance length in French. Phonetica 26. 235-251.

McCarthy, John \& Alan Prince. 1995. Generalized alignment. In Geert Booij \& Jaap van Merle (eds.) Yearbook of Morphology. 79-153.

Nakatani, Lloyd H., Kathleen D. O'Connor \& Carletta H. Aston. 1981. Prosodic aspects of American English speech rhythm. Phonetica 38. 84-106.

Nespor, Marina \& Irene Vogel. 1986. Prosodic phonology. Dordrecht: Foris.

R Development Core Team. 2018. R: A language and environment for statistical computing. Vienna, Austria.

Scullen, Mary Ellen. 1997. French prosodic morphology: A unified account. Bloomington: Indiana University Linguistics Club.

Thibault, Linda \& Marise Ouellet. 1996. Tonal distinctions between emphatic stress and pretonic lengthening in Quebec French. Proceedings of the International Spoken Language Conference 1996. 638-641.

Verluyten, Sylvain Paul Marcel. 1982. Recherches sur la prosodie et la métrique du français. $\mathrm{PhD}$ dissertation, Universiteit Antwerpen.

Vogel, Irene. 2009. The status of the clitic group. In Janet Grijzenhout \& Baris Kabak (eds.), Phonological domains: Universals and deviations. 15-46. Berlin: Mouton de Gruyter.

Walker, Douglas C. 1984. The pronunciation of Canadian French. Ottawa: University of Ottawa Press. 